\title{
Preparation and characterization of water-redispersible nanofibrillated cellulose in powder form
}

\author{
Ch. Eyholzer $\cdot$ N. Bordeanu $\cdot$ F. Lopez-Suevos $\cdot$ \\ D. Rentsch $\cdot$ T. Zimmermann $\cdot$ K. Oksman
}

Received: 16 July 2009/Accepted: 5 October 2009/Published online: 20 November 2009

(C) Springer Science+Business Media B.V. 2009

\begin{abstract}
Water-redispersible, nanofibrillated cellulose (NFC) in powder form was prepared from refined, bleached beech pulp (RBP) by carboxymethylation (c) and mechanical disintegration (m). Two routes were examined by altering the sequence of the chemical and mechanical treatment, leading to four different products: RBP-m and RBP-mc (route 1), and RBP-c and RBP-cm (route 2). The occurrence of the carboxymethylation reaction was confirmed by FT-IR spectrometry and ${ }^{13} \mathrm{C}$ solid state NMR $\left({ }^{13} \mathrm{C}\right.$ CP-MAS) spectroscopy with the appearance of characteristic signals for the carboxylate group at $1,595 \mathrm{~cm}^{-1}$ and $180 \mathrm{ppm}$, respectively. The chemical modification reduced the crystallinity of the products, especially for those of route 2 , as shown by XRD experiments. Also, TGA showed a decrease in the thermal stability of the carboxymethylated products. However, sedimentation tests revealed that carboxymethylation was critical to obtain water-redispersible powders: the products of route 2 were easier to redisperse in water and their aqueous suspensions
\end{abstract}

Ch. Eyholzer $(\bowtie) \cdot$ N. Bordeanu · F. Lopez-Suevos · D. Rentsch · T. Zimmermann

Swiss Federal Laboratories for Materials Testing and Research (EMPA), Dübendorf, Switzerland

e-mail: christian.eyholzer@empa.ch

Ch. Eyholzer · K. Oksman

Division of Manufacturing and Design of Wood and Bionanocomposites, Luleå University of Technology (LTU), Luleå, Sweden were more stable and transparent than those from route 1. SEM images of freeze-dried suspensions from redispersed RBP powders confirmed that carboxymethylation prevented irreversible agglomeration of cellulose fibrils during drying. These results suggest that carboxymethylated and mechanically disintegrated RBP in dry form is a very attractive alternative to conventional NFC aqueous suspensions as starting material for derivatization and compounding with (bio)polymers.

Keywords Cellulose - Carboxymethylation · Mechanical disintegration - Nanofibrils . Hornification · Water-redispersible

\section{Introduction}

Nanofibrillated cellulose (NFC) has attracted great interest for the preparation of nanocomposites with polymer matrices due to its interesting properties, such as high strength and stiffness (Zadorecki and Michell 1989; Yano and Nakahara 2004; Hubbe et al. 2008), transparency (Yano et al. 2005) or biodegradability (Couderc et al. 2009). The isolation of NFC from wood pulp has been achieved by applying mechanical treatment, using a high-pressure homogenizer (Turbak et al. 1983; Herrick et al. 1983; Wågberg et al. 1987; Pääkkö et al. 2007) or grinding with previous chemical treatment (Abe et al. 2007; Saito et al. 2006). However, the hydrophilic nature of 
cellulose causes two major issues, namely, irreversible agglomeration during drying and agglomeration of NFC in non-polar matrices during compounding.

Irreversible agglomeration of cellulose during drying is called hornification (Young 1994; Hult et al. 2001) and is explained by the formation of additional hydrogen bonds between amorphous parts of the cellulose fibrils during drying. The formation of these bonds correlates with the amount of water removed, and does not depend directly on temperature. As in the crystalline parts of cellulose, water cannot break the formed hydrogen bonds during rewetting of hornificated cellulose (Scallan and Tigerström 1992; Laivins and Scallan 1993). To prevent hornification, isolation of NFC is preferentially done by mechanical disintegration of neverdried pulp in an aqueous suspension. So far, to the best of the authors' knowledge, there is only one commercially available NFC product of high quality (Celish, Daicel Chemical Industries, Osaka, Japan), which is delivered as a $10-35 \%$ (w/w) aqueous suspension. The ramifications of producing NFC in aqueous suspensions are high shipping costs, large storage facilities and propensity towards bacterial decomposition. Consequently, the preparation of a nanofibrillated cellulose powder, which can be easily dispersed in water avoiding hornification, would be of great industrial interest from both economical and ecological points of view. Also, the general interest in preparing NFC powder avoiding hornification has been evidenced in several patents (Herrick 1984; Bahia 1995; Dinand et al. 1996; Excoffier et al. 1999; Cantiani et al. 2001; Cash et al. 2003; Bordeanu et al. 2008). Basically, the main strategy is prevention of increased hydrogen bond formation between cellulose fibrils by introducing steric and electrostatic groups. These groups increase the accessibility and affinity of water towards the fibrils.

The second issue is agglomeration of NFC in hydrophobic polymers during compounding. Again it is the large number of hydrogen bonds that can be formed between the cellulose fibrils that prevent a homogeneous distribution of NFC within a non-polar polymer matrix. Therefore, the aspect ratio of these NFC agglomerates is drastically reduced, causing a strong decrease in their reinforcing potential (Boldizar et al. 1987; Chakraborty et al. 2006). In order to improve compatibility at the fiber-matrix interface, chemical modification of cellulose hydroxyl groups is a viable and widely used approach. Various methods to modify the surface of NFC were reported, such as silylation (Goussé et al. 2004; Andresen et al. 2006), TEMPO oxidation (Saito et al. 2006; Araki et al. 2001; Lasseuguette 2008), acetylation (Sassi and Chanzy 1995) or reactions with anhydrides (Stenstad et al. 2008).

Partial carboxymethylation of the NFC hydroxyl groups can overcome hornification during drying, provided that the carboxylic groups are present in their sodium form (Lindström and Carlsson 1982; Laivins and Scallan 1993). Also, this effect depends on the degree of substitution (DS) which is defined by the ratio of reacted carboxyl groups per anhydroglucose units (AGU). The DS of commercially available carboxymethyl cellulose (CMC) is usually between 0.5 and 1.0 but mainly around 0.9 . Such highly water-soluble CMC is well-known as a thickening agent in food, as an additive in pharmaceutics, cosmetics and detergents, but also as a component of membranes or drilling mud for water retention. Below a DS of 0.3-0.4, CMC is insoluble in water, however, such low-DS CMC show higher water absorbance and swelling in water than the original cellulose, even if the DS is only 0.025 (Walecka 1956; Reid and Daul 1947). In addition to the prevention of hornification, carboxymethylation could possibly also prevent agglomeration of the NFC during compounding with polymers. However, further chemical modification to enhance the chemical affinity of the NFC to different non-polar polymer matrices might be necessary.

In the present work, two routes for the preparation of dry, water-redispersible NFC are compared by altering the sequence of the chemical and mechanical treatment of a commercial, refined beech pulp (RBP). The resulting modified and unmodified RBP powders were analyzed by FT-IR, ${ }^{13} \mathrm{C}$ solid state NMR $\left({ }^{13} \mathrm{C}\right.$ CP-MAS), XRD and TGA in order to learn more about their chemical structure and thermal stability. Also, after dispersing the RBP powders in water, sedimentation studies were conducted to evaluate the stability of the different suspensions. Finally, the redispersed RBP suspensions were freeze-dried and their morphologies were analyzed by the SEM.

\section{Materials and methods}

Refined, bleached beech pulp (RBP) was provided by J. Rettenmaier \& Söhne GmbH, Rosenberg, Germany 
(Arbocel B1011, 10.0\% w/w aqueous suspension, $\mathrm{M}_{\mathrm{AGU}}$ (anhydroglucose unit) = $162 \mathrm{~g} / \mathrm{mol}$ ). Chloroacetic acid (sodium salt, purity $\geq 98 \%, \quad M=$ $116.48 \mathrm{~g} / \mathrm{mol}$ ) and sodium hydroxide $(\mathrm{NaOH}$, purity $\geq 98 \%, M=40.0 \mathrm{~g} / \mathrm{mol}$ ) were purchased from Merck and Fluka, respectively.

\section{Mechanical disintegration}

Preparation of RBP-m (route 1) was performed in a $10 \mathrm{~L}$ glass reactor, equipped with an inline UltraTurrax system (Megatron MT 3,000, Kinematica AG, Luzern, Switzerland), and in a high-shear homogenizer (Microfluidizer type M-110Y, Microfluidics Corporation, USA). $2.0 \mathrm{~kg}$ of the $10 \% \mathrm{w} / \mathrm{w}$ aqueous RBP were diluted to $2.0 \% \mathrm{w} / \mathrm{w}$ with $8.0 \mathrm{~kg}$ of deionised water and allowed to swell for one week at $20{ }^{\circ} \mathrm{C}$, followed by $2 \mathrm{~h}$ of homogenization using the Ultra-Turrax system $(20,000 \mathrm{rpm})$. The suspension was diluted with deionised water to $1.75 \% \mathrm{w} / \mathrm{w}$ and pumped through a $\mathrm{H} 230 \mathrm{Z}_{400 \mu \mathrm{m}}$ and a $\mathrm{H} 30 \mathrm{Z}_{200 \mu \mathrm{m}}$ chamber for 6 passes, followed by another 4 passes through a $\mathrm{H} 230 \mathrm{Z}_{400 \mu \mathrm{m}}$ and a $\mathrm{F} 20 \mathrm{Y}_{75 \mu \mathrm{m}}$ chamber. The processing pressure inside the F20Y chamber was calculated to approximately $125 \mathrm{MPa}$. The resulting RBP-m suspension was then concentrated to a dry material content of $10.0 \%$ in a centrifuge (5,000 rpm, $\left.15^{\circ} \mathrm{C}, 45 \mathrm{~min}\right)$.

For the preparation of RBP-cm (route 2), $8.75 \mathrm{~g}$ of RBP-c (solid, preparation described below) were used as starting material. The RBP-c powder was dispersed in $500 \mathrm{ml}$ of deionised water to a final concentration of $1.75 \% \mathrm{w} / \mathrm{w}$ and homogenized with a blender (T 25 basic, IKA-Werke, Staufen, Germany). In general, the mechanical treatment of the resulting suspension was performed as previously described for route 1 . However, the disintegration treatment was stopped after only 2-3 passes through the $\mathrm{H}_{2} 30 \mathrm{Z}_{400 \mu \mathrm{m}}$ and $\mathrm{F} 20 \mathrm{Y}_{75 \mu \mathrm{m}}$ chambers since the resulting gel became too viscous for further processing.

\section{Chemical modification}

Preparation of RBP-mc (route 1) was performed in a $10 \mathrm{~L}$ glass reactor, equipped with the Ultra-Turrax system and a mechanical stirrer. $700 \mathrm{~g}$ of the $10 \%$ w/w aqueous RBP-m suspension (0.432 mol AGU) was transferred into the reactor. $6.2 \mathrm{~L}$ of a $5 / 3 \mathrm{v} / \mathrm{v}$ isopropanol/ethanol mixture was added to obtain a final cellulose concentration of $1.27 \% \mathrm{w} / \mathrm{w}$. The suspension was homogenized, using the Ultra-Turrax system $\left(10,000 \mathrm{rpm} ; 20{ }^{\circ} \mathrm{C}\right)$. After $15 \mathrm{~min}, 303 \mathrm{~g}$ of a $5.0 \% \mathrm{w} / \mathrm{w} \mathrm{NaOH}$ aqueous solution $(0.4 \mathrm{~mol})$ was added dropwise to the RBP-m for $30 \mathrm{~min}$ to activate the cellulose. Then, $25.1 \mathrm{~g}$ of chloroacetic acid (sodium salt; $0.216 \mathrm{~mol}$ ) was added to the activated RBP. The mixture was heated to $60{ }^{\circ} \mathrm{C}$ under stirring, without using the Ultra-Turrax system. The reaction was stopped after $2 \mathrm{~h}$ by cooling it to room temperature and the $\mathrm{pH}$ of the suspension was adjusted to neutrality with acetic acid.

Preparation of RBP-c (route 2) was performed with $700 \mathrm{~g}$ of the $10 \% \mathrm{w} / \mathrm{w}$ RBP aqueous suspension (0.432 mol AGU) as starting material. In this case, $198 \mathrm{~g}$ of a $5.0 \% \mathrm{w} / \mathrm{w}$ aqueous $\mathrm{NaOH}$ solution $(0.25 \mathrm{~mol})$ and $14.85 \mathrm{~g}$ of chloroacetic acid (sodium salt; $0.127 \mathrm{~mol}$ ) was used.

Purification of RBP-mc and RBP-c was done by washing them several times with different solutions (described below) and centrifugation $(5,000 \mathrm{rpm}$, $15{ }^{\circ} \mathrm{C}, 45 \mathrm{~min}$ ). First, the glycolic acid (by-product) was removed with a $1 / 1 \mathrm{v} / \mathrm{v}$ mixture of $0.05 \mathrm{M}$ aqueous acetic acid and 5/3 v/v isopropanol/ethanol. Second, the carboxyl groups of the modified cellulose were deprotonated with a $1 / 1 \mathrm{v} / \mathrm{v}$ mixture of $0.05 \mathrm{M}$ aqueous $\mathrm{NaOH}$ and $5 / 3 \mathrm{v} / \mathrm{v}$ isopropanol/ethanol. Finally, the remaining salts were washed off with a $1 / 1 \mathrm{v} / \mathrm{v}$ mixture of deionised water and $5 / 3 \mathrm{v} / \mathrm{v}$ isopropanol/ethanol. It was ensured that the $\mathrm{pH}$ of the last supernatant did not drop below 8.0.

\section{Drying of cellulose suspensions}

To obtain cellulose powders from aqueous suspensions of the various samples, a two steps procedure was applied. First, the solvent of the aqueous suspensions was exchanged from deionised water to a $5: 3 \mathrm{v} / \mathrm{v}$ isopropanol/ethanol mixture in several washing and centrifugation steps $\left(5,000 \mathrm{rpm}, 15^{\circ} \mathrm{C}\right.$, $45 \mathrm{~min}$ ). Then, the suspensions were stirred several times with a glass bar during drying in an oven at $60{ }^{\circ} \mathrm{C}$, until a fine powder of constant weight was obtained. 
Determination of the degree of substitution (DS)

Conductometric titration (CT) was used to calculate the DS of carboxymethylated RBP following the protocol of Eyler (Eyler et al. 1947) with slight modifications. $0.3 \mathrm{~g}$ of dried, carboxymethylated cellulose fibrils were redispersed in $60.0 \mathrm{~g}$ of deionised water using a blender. Then, $5.0 \mathrm{ml}$ of a $0.1 \mathrm{M}$ aqueous $\mathrm{NaOH}$ solution was added to the suspension and stirred with a magnetic bar. The conductivity of the suspension was measured upon titration with $10.0 \mathrm{ml}$ of a $0.1 \mathrm{M}$ aqueous hydrochloric acid $(\mathrm{HCl})$ solution, using a Metrohm conductometer (model 1.712.0010, Metrohm AG, Herisau, Switzerland), equipped with a platinum electrode (model 6.0309.100). The measurements were repeated three times for each sample. The experimental DS values for RBP-mc $(0.087 \pm 0.002), \quad$ RBP-c $\quad(0.130 \pm$ $0.001)$ and RBP-cm $(0.138 \pm 0.002)$ were significantly lower than those expected stoichiometrically ( 0.3 and 0.5 , respectively). This difference can be attributed to the partial deactivation of monochloroacetic acid with water during the reaction and the loss of some higher substituted, water-soluble NFC during purification.

Fourier transform-infrared spectroscopy (FT-IR)

Powder samples were measured after drying at $60{ }^{\circ} \mathrm{C}$. The spectra were recorded using a Digilab BioRad FTS 6000 Spectrometer (Philadelphia, USA) in single reflection diamond ATR (Attenuated Total Reflectance) mode (P/N 10,500 series, golden gate). The number of scans was 32 and the resolution was $4 \mathrm{~cm}^{-1}$.

Solid-state ${ }^{13} \mathrm{C}$ CP-MAS NMR spectroscopy

(Cross Polarization Magic Angle Spinning

Nuclear Magnetic Resonance)

The ${ }^{13} \mathrm{C}$ CP-MAS NMR spectra of the RBP samples were measured at $100.61 \mathrm{MHz}$ on a Bruker AVANCE -400 MHz NMR Spectrometer (Bruker BioSpin AG, Fällanden, Switzerland) using a $7 \mathrm{~mm}$ broadband CPMAS probe. The following parameters were used: MAS rates of $3,000 \mathrm{~Hz}, \mathrm{CP}-\mathrm{MAS}$ contact times of $3 \mathrm{~ms}, 8 \mathrm{~s}$ relaxation delays, number of accumulated free induction decays (FID) $>20,000$ (for a reasonable signal to noise ratio of the carbonyl resonances,
2,134 for the untreated RBP) applying $38 \mathrm{kHz}$ TPPM decoupling of ${ }^{1} \mathrm{H}$ during acquisition. The FIDs were multiplied by an exponential window function of $50 \mathrm{~Hz}$ before Fourier Transformation.

\section{X-Ray diffraction (XRD)}

For each RBP, three pellets were prepared by applying $3 \mathrm{t}$ of weight to $750 \mathrm{mg}$ of powder for $2 \mathrm{~min}$. The pellets were measured in reflection mode, using an X'Pert Pro diffractometer from Panalytical (Almelo, Netherlands) with $\mathrm{Cu} \mathrm{K}_{\alpha}$ radiation $(\lambda=$ $1.5418 \AA)$ in combination with a linear detector system (X'Celerator).

Thermogravimetric analysis (TGA)

Degradation behavior of the treated and untreated RBP was analyzed using a NETZSCH TG 209 F1 (Netzsch Group, Selb, Germany) in dry gas nitrogen atmosphere. The heating rate was $20{ }^{\circ} \mathrm{C} / \mathrm{min}$.

Scanning electron microscopy (SEM)

The prepared cellulose powders of both routes were redispersed in water to a final concentration of $0.1 \% \mathrm{w} / \mathrm{w}$ and homogenized with a blender. Then, a sample holder on which a fresh mica plate had been fixed with liquid carbon cement was cooled down in liquid nitrogen. Immediately after removing the sample holder plate, droplets of the $0.1 \% \mathrm{w} / \mathrm{w}$ suspensions of the treated and untreated RBP in water were placed onto the surface with a syringe. The frozen sample was then kept under vacuum (below $1 \times 10^{-1}$ mbar) until the ice was sublimated. The freeze-dried RBP samples were then sputtered with a $4 \mathrm{~nm}$ platinum coating. Images were recorded in a JEOL JSM-6300F (Jeol Ltd., Tokyo, Japan) equipped with a cold-cathode field emission gun. The following parameters were used: acceleration voltage of $5.0 \mathrm{kV}$, probe current of $6 \times 10^{-11} \mathrm{~A}$, working distance of $48 \mathrm{~mm}$. Of each suspension, three droplets were analyzed. All images were recorded in the center of the droplets.

\section{Results and discussion}

Two processing routes (Fig. 1) were proposed to prepare nanofibrillated cellulose powder, capable of 


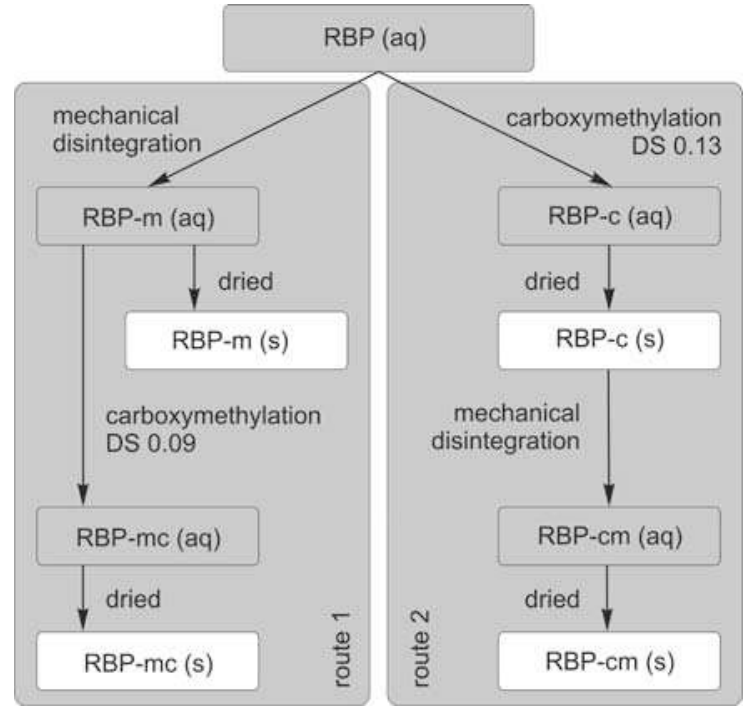

Fig. 1 Schematic overview on the sample preparation routes. In route 1 (left block), the untreated RBP is mechanically disintegrated (RBP-m), followed by carboxymethylation (RBP$\mathrm{mc}$ ). In route 2 (right block), the treatments are interchanged. The untreated RBP was first carboxymethylated (RBP-c), then dried to a powder, redispersed in water and finally mechanically disintegrated (RBP-cm). Aqueous suspensions (grey) are intermediate products

forming a stable suspension after redispersion in water. Mechanical disintegration of the pulp was done either before (route 1) or after (route 2) carboxymethylation (Fig. 2). Good redispersibility of the final RBP powder in water depended on the drying procedure and the DS of the CMC. Drying CMC from a 5:3 v/v isopropanol/ethanol mixture at $60{ }^{\circ} \mathrm{C}$ under occasional stirring with a glass bar led to a highly porous and fluffy powder with a significantly higher volume compared to those dried from aqueous suspensions or without stirring. This can directly account for the enhanced redispersibility of the powders in water, being able to more easily penetrate the more open structure of the cellulose. The use of a blender for several seconds of course accelerates the re-wetting of the cellulose. No further treatment (e.g.

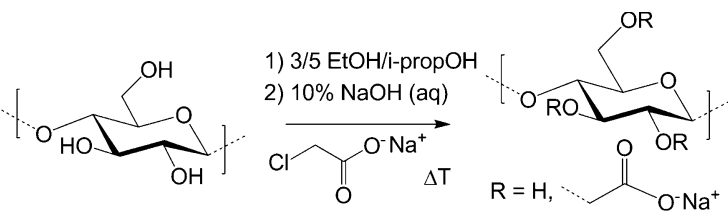

Fig. 2 Carboxymethylation of cellulose with chloroacetic acid freeze-drying, vacuum drying or spray-drying) was necessary to obtain redispersible powders. However, some of the mentioned methods might also lead to redispersible $\mathrm{CMC}$ powders when the suspensions are dried from an alcohol mixture. As a second criterion, the DS must be high enough to prevent hornification during drying but sufficiently low to prevent solubilisation during water redispersion. Therefore, preliminary experiments were performed to select an appropriate DS that would satisfy the above requirements. Briefly, the selected experimental DS for RBP-mc (route 1) and RBP-cm (route 2) were 0.09 and 0.13 , respectively.

To confirm successful carboxymethylation reaction, the powdered treated and untreated RBP were characterized using FT-IR spectroscopy (Fig. 3a). The spectrum of the untreated RBP showed the characteristic absorption bands of cellulose. A large band between 3,600 and $2,800 \mathrm{~cm}^{-1}$ contains $\mathrm{CH}$ stretching vibrations, and $\mathrm{OH}$ stretching vibrations from alcoholic groups and water. The broad band with a peak at $1,640 \mathrm{~cm}^{-1}$ was attributed to the bending vibrations of adsorbed water. A series of peaks between 1,500 and $1,300 \mathrm{~cm}^{-1}$ were associated to $\mathrm{OCH}$ deformation vibrations, $\mathrm{CH}_{2}$ bending vibrations and $\mathrm{CCH}$ and $\mathrm{COH}$ bending vibrations. Finally, the band ranging from 1,200 to $900 \mathrm{~cm}^{-1}$ mainly contains the signals of $\mathrm{CC}$ stretching vibrations and $\mathrm{COH}$ and $\mathrm{CCH}$ deformation vibrations (Proniewicz et al. 2001). Mechanical disintegration of the RBP (RBP-m) did not lead to a change in the FT-IR spectrum. However, chemical modification of the RBP (RBP-mc, RBP-c and RBP-cm) led to the appearance of a new signal at $1,595 \mathrm{~cm}^{-1}$, which was attributed to the asymmetric stretching vibration of the carboxylate group (Cuba-Chiem et al. 2008), confirming the successful carboxymethylation. As it can be observed, the intensity of the $1,595 \mathrm{~cm}^{-1}$ signal for the RBP-mc (route 1) is lower than those for the RBP-c and RBP-cm (route 2). This is in agreement with the experimental DS values previously reported where the DS for the RBP-mc was also lower than the one for the RBP-c.

CP-MAS ${ }^{13} \mathrm{C}$-NMR was used to support the findings of the FT-IR experiments. Figure $3 b$ shows the spectra of the untreated RBP and the treated RBP products of both routes in the region from 0 to $220 \mathrm{ppm}$. Also, an inset graph showing the region where the carboxylate signal appears (around 
Fig. 3 a FT-IR and $\mathbf{b}{ }^{13} \mathrm{C}$ CP-MAS NMR spectra of treated and untreated RBP

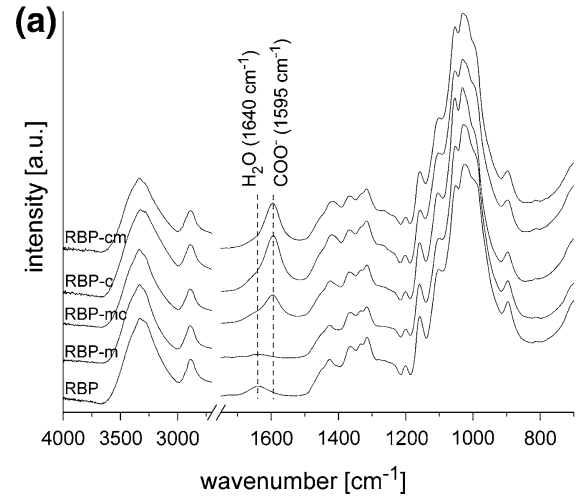

$180 \mathrm{ppm}$ ) is included. Again, the RBP material shows the characteristic signal pattern of cellulose: $C_{1}$ (106 ppm), $\mathrm{C}_{4}$ (90 and $85 \mathrm{ppm}$, from crystalline and amorphous domains, respectively), overlapped signals of $\mathrm{C}_{2}, \mathrm{C}_{3}$ and $\mathrm{C}_{5}$ (between 70 and $80 \mathrm{ppm}$ ) and $\mathrm{C}_{6}$ (66 ppm) (Gilardi et al. 1995; Kono et al. 2002). As expected, mechanical disintegration of RBP (RBP-m) did not promote changes in the chemical structure as all the NMR signals are identical. However, carboxymethylated RBP samples (RBP-mc, RBP-c and RBP-cm) showed a new signal at $180 \mathrm{ppm}$, which was attributed to the carboxylate group (Heinze and Koschella 2005). This peak is again more pronounced for the samples with higher DS, i.e. the RBP-c and the RBP-cm. Finally, the resonances marked with a star are spinning side bands of the carboxylate groups (210 and $150 \mathrm{ppm})$ and of the $\mathrm{C}_{1}(136 \mathrm{ppm})$, respectively. Overall, the occurrence of the carboxymethylation reaction on the RBP samples was successfully evidenced by CT, FT-IR and CP-MAS ${ }^{13} \mathrm{C}-\mathrm{NMR}$ analyses.

Chemical modification of cellulose can decrease its crystallinity (Sassi and Chanzy 1995) leading to a possible reduction of its reinforcing potential in composites with polymers. The effect of the mechanical and chemical treatments on the crystallinity of the different samples was analyzed by X-ray diffraction (Fig. 4a). The diffractogram of the untreated RBP shows reflections of the cellulose lattice planes appearing at $2 \theta$ angles between $13^{\circ}$ and $17^{\circ}(1 \overline{1} 0$ and $110), 22.3^{\circ}(020)$ and $34.5^{\circ}(004)$ (Sassi and Chanzy 1995). The crystallinity $\chi_{\mathrm{cr}}$ of the samples was estimated by using Eq. 1 (Segal et al. 1959) with $I_{020}$ being the intensity of the 020 peak (amorphous and crystalline reflections at $22.3^{\circ}$ ) and $I_{\text {am }}$ being the intensity of the minimum between the 020 and 110 peaks (amorphous reflections at $18.5^{\circ}$ ).

$\chi_{\mathrm{cr}}=\frac{I_{020}-I_{\mathrm{am}}}{I_{020}}$.

This method assumes that the amorphous part of the cellulose shows equal intensity at both $2 \theta$ angles, $18.5^{\circ}$ and $22.3^{\circ}$, respectively. It also assumes that there is no portion of crystalline reflection at $18.5^{\circ}$. The highest value of crystallinity was obtained for RBP raw with $71 \%$, followed by RBP-m (68\%), RBP-mc (65\%), RBP-c (63\%) and RBP-cm (49\%). As it can be observed, samples from route 1 (RBP-m and RBP-mc) showed very similar crystallinity values, implying that the crystalline structure was not significantly affected. However, samples from route 2 (RBP-c and RBP-cm), presented a more pronounced reduction in crystallinity. Consequently, mechanical disintegration had a stronger effect on crystallinity when the cellulose was carboxymethylated first. Apparently, the presence of the carboxylate groups makes the mechanical isolation more efficient, as not only amorphous parts but also crystalline domains are affected by the treatment. Increased efficiency for isolation of fibrillated material can be explained by ionic repulsion between the carboxylate groups of the single cellulose chains (Wågberg et al. 2008). Lower forces would therefore be sufficient to isolate the nanofibrillated material.

Another cause for reduction of the NFC reinforcing potential can be thermal degradation of NFC during compounding with polymers at high temperatures, i.e. by extrusion. Therefore, the thermal stability of the RBP samples was evaluated by TGA in dry gas nitrogen (Fig. 4b). As it can be observed, 
Fig. 4 a XRD

diffractograms, b TGA spectra and c DTG spectra of treated and untreated RBP

(a)

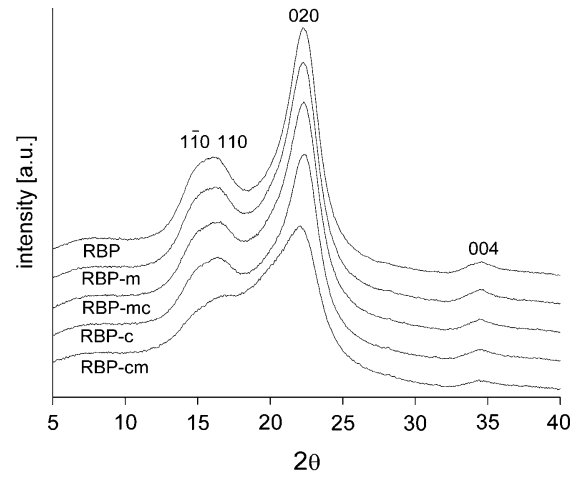

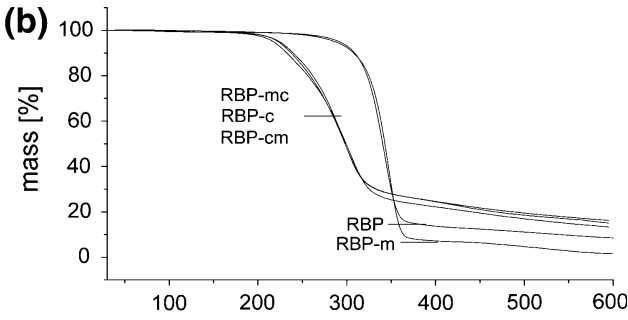

(c)

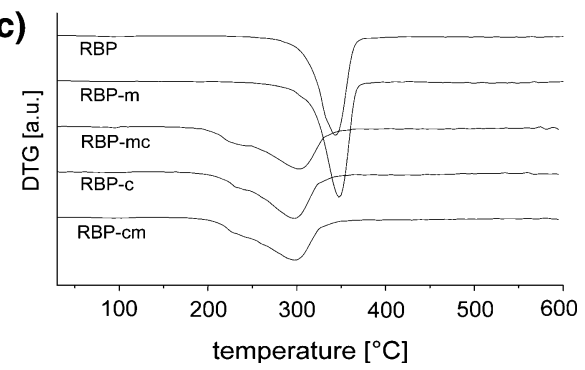

the onset temperature of cellulose degradation was around $250{ }^{\circ} \mathrm{C}$ for the untreated RBP (top graph, weight loss curve) with a sharp degradation peak at $345^{\circ} \mathrm{C}$ in the DTG (Fig. 4c, weight loss rate curve) at a heating rate of $20{ }^{\circ} \mathrm{C} / \mathrm{min}$. During the thermal degradation process, cellulose is converted into volatiles, tars and charcoal (Shafizadeh and McGinnis 1971). Mechanical disintegration of RBP (RBP-m) did not lead to significant changes in the characteristic degradation temperatures. However, chemical modification of the RBP (i.e. RBP-mc, RBP-c and $\mathrm{RBP}-\mathrm{cm}$ ) led to a decrease of both the onset degradation temperature and the degradation peak to 200 and $300{ }^{\circ} \mathrm{C}$, respectively. Consequently, carboxymethylation clearly reduced the thermal stability of the studied products. This finding is in agreement with the results obtained from thermal degradation of TEMPO-mediated, oxidized cellulose (Fukuzumi et al. 2009) and of partially carboxymethylated cellulose (Lourdes-Leza et al. 1989).

The ability of the samples to form stable suspensions or gels in water was evaluated by qualitatively analyzing the sedimentation rate of the suspensions. Figure 5 shows testing tubes with $0.2 \%$ w/w (left series) and $1.0 \% \mathrm{w} / \mathrm{w}$ (right series) concentrations of redispersed RBP samples in water. After transferring the suspensions into the testing tubes, photographs were taken at $0 \mathrm{~min}, 15 \mathrm{~min}, 1 \mathrm{~h}$ and $20 \mathrm{~h}$. At $0.2 \%$ concentration, complete sedimentation of the untreated RBP and the RBP-m occurred within $15 \mathrm{~min}$ and $1 \mathrm{~h}$, respectively. In contrast, the suspensions of the carboxymethylated RBP suspensions (RBP-mc, RBP-c and RBP-cm) were stable for at least $1 \mathrm{~h}$, with the RBP-cm being stable for the
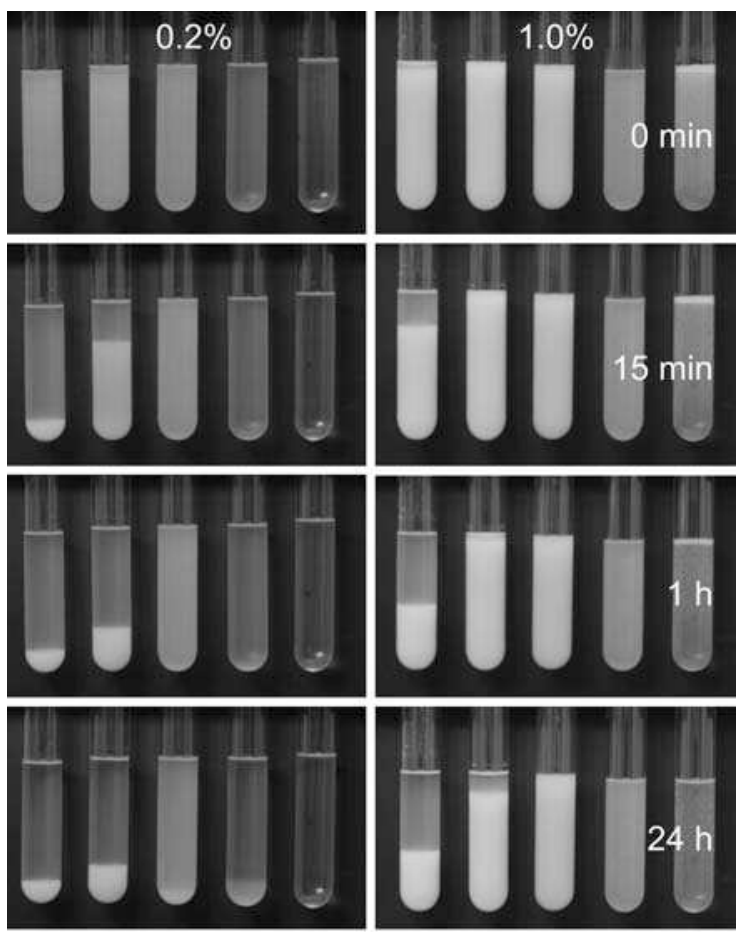

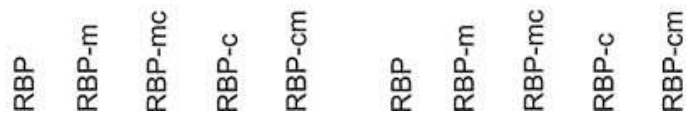

Fig. 5 Time-dependent sedimentation experiments of treated and untreated RBP in concentrations of 0.2 and $1.0 \%$ 
whole studied period of time (i.e. $20 \mathrm{~h}$ ). It should be noted that the stability of a carboxymethylated NFC suspension is susceptible to its $\mathrm{pH}$ and salt concentration (Wågberg et al. 2008). At 1.0\% concentration, differences in the sedimentation behavior of the different RBP suspensions were more difficult to observe. However, differences in transparency of the suspensions became more distinct. Samples from route 1 (RBP-m and RBP-mc) formed a white suspension, whereas samples from route 2 (RBP-c and RBP-cm) were more transparent. The transparency of RBP-cm indicates that the dimensions of a major part of cellulose particles in the suspension were below the limit for light-scattering. This was verified by SEM characterization of the redispersed suspensions after freeze-drying (Fig. 6). The untreated RBP (a) formed large aggregates which were not dispersed in the suspension. This is in agreement with the much faster sedimentation rate of the RBP suspension compared to the other samples. RBP-m (b) did also form some aggregates, although they were smaller and some fibrils with diameters below the micrometer range remained isolated. Carboxymethylation of this sample (RBP-mc) did not lead to significant changes in the morphology of the freeze-dried cellulose. In contrast, RBP-c (d) formed a network of cellulose fibrils with overall diameters below 1 micron. The SEM image of
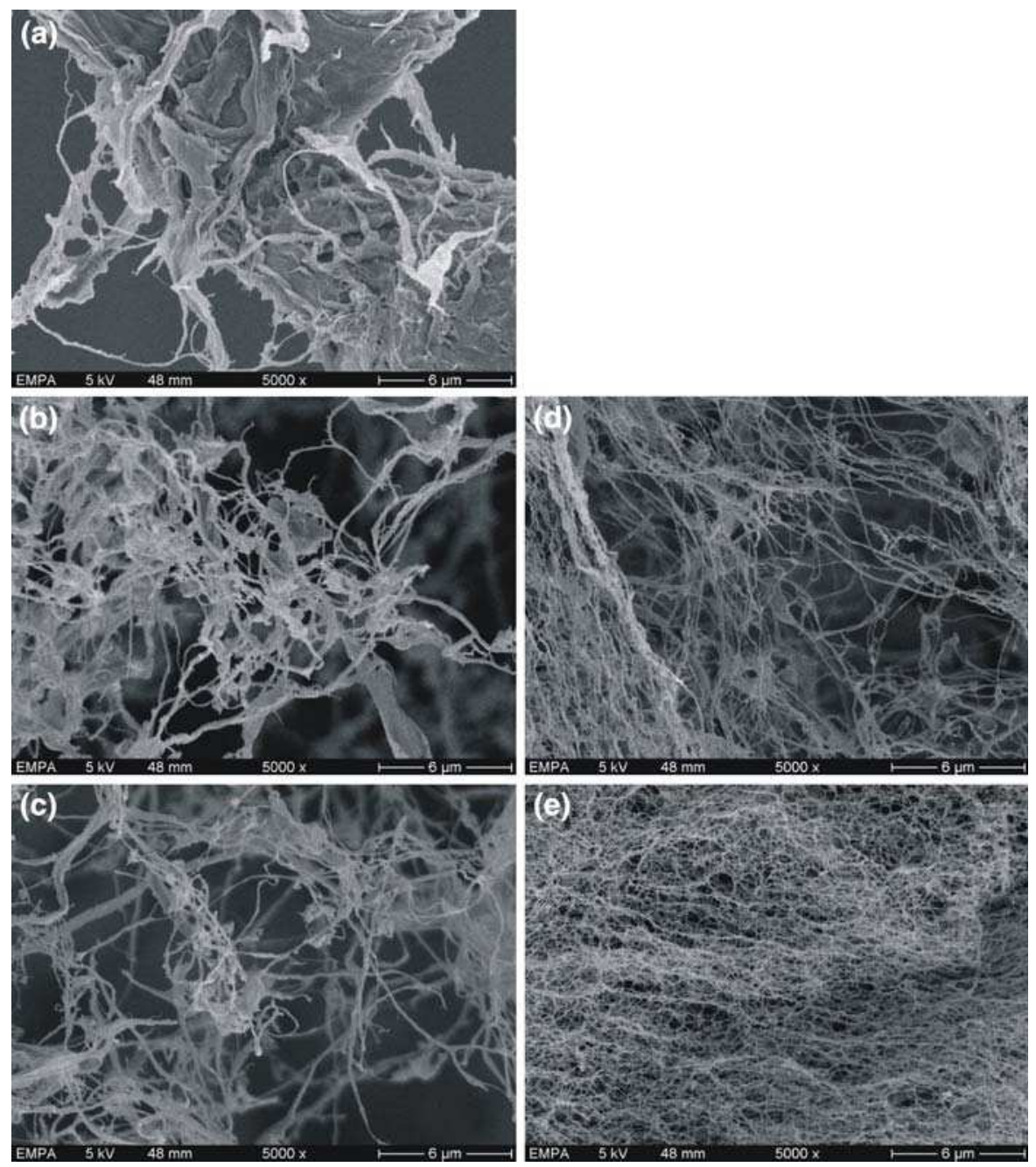

Fig. 6 SEM-images of water-redispersed and freeze-dried RBP samples at a magnification of $\times 5000, \mathbf{a}$ RBP, b RBP-m, $\mathbf{c}$ RBP-mc, d RBP-c and e RBP-cm 


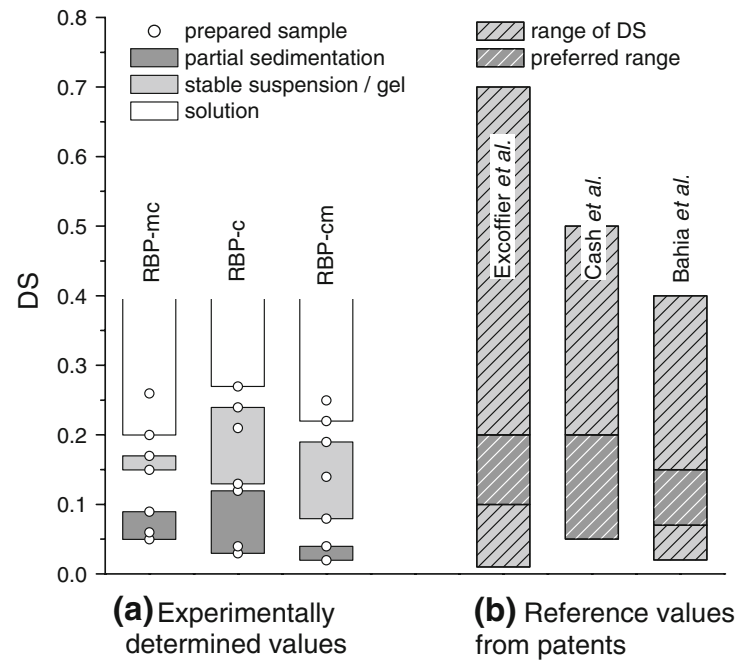

Fig. 7 a Appearance of treated RBP aqueous suspensions at $0.2 \% \mathrm{w} / \mathrm{w}$ compared with $\mathbf{b}$ the covered range of DS of carboxymethylated and mechanically disintegrated cellulose and the "preferred values" of DS, reported in patents

freeze-dried RBP-cm (e) showed a coherent system of cellulose nanofibrils, with overall diameters below $100 \mathrm{~nm}$. The samples from route 2 (RBP-c and RBP$\mathrm{cm})$ showed clearly less agglomeration of the fibrils, which also were lower in diameter, compared to those of route 1 (RBP-m and RBP-mc). This also accounts for the increased stability of the suspensions from this route, as presented above.
The appearance of the redispersed CMC aqueous suspensions with respect to their DS is shown in Fig. 7a. A series of seven samples with varying DS was prepared for each carboxymethylated product (RBP-mc, RBP-c and RBP-cm). The various DS of the prepared powders are indicated by empty circles. The powders were dispersed in water at concentrations of $0.2 \% \mathrm{w} / \mathrm{w}$ and $1.0 \% \mathrm{w} / \mathrm{w}$ (data for $1.0 \% \mathrm{w} / \mathrm{w}$ not shown) and photographs were taken of the suspensions after $20 \mathrm{~h}$ (Fig. 8). The suspensions were then categorized into three classes, i.e. solutions (white), stable suspensions or gels (light grey) and suspensions showing partial sedimentation (dark grey). The suspensions with a concentration of $1.0 \% \mathrm{w} / \mathrm{w}$ were stable for the whole time range and no phase-separation or sedimentation was observed. However, at lower concentration $(0.2 \% \mathrm{w} / \mathrm{w})$, the differences between the samples became more evident: At low DS (between 0.05 and 0.09 for RBP-mc, 0.03 and 0.12 for RBP-c and 0.02 and 0.04 for RBP$\mathrm{cm})$ the translucent suspensions showed opaque, white sediments which were more pronounced in the RBP-c series. This partial sedimentation can be explained by local hornification due to the inhomogeneous substitution pattern at low substituted carboxymethyl celluloses (Walecka 1956). It is worth to note that pre-mechanical carboxymethylation (RBP$\mathrm{cm}$, route 2) seems to clearly reduce the level below
Fig. 8 Photographs of water-redispersed, treated RBP with various DS, at concentrations of 0.2 and $1.0 \%$ after $20 \mathrm{~h}$
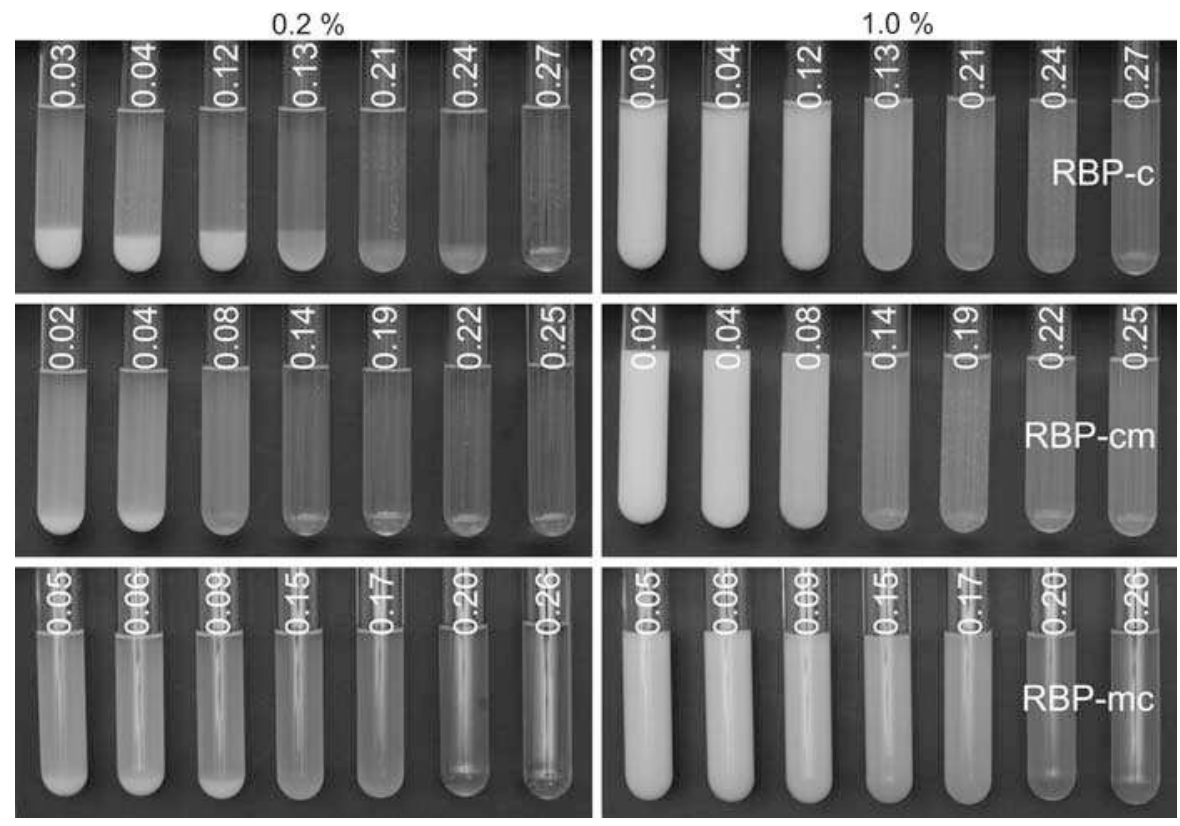
which hornification occurs. Also, it was reported that carboxymethylated, bleached sulfate pulp shows hornification below a DS of around 0.05 (Lindström and Carlsson 1982). At higher DS (between 0.15 and 0.17 for RBP-mc and 0.08 and 0.22 for RBP-cm) the suspensions were stable and almost transparent. Only the suspensions of RBP-c (between 0.13 and 0.24) showed some translucent sediments. Still, these suspensions were qualified as stable because of the small volumes and translucence of the sediments. Interestingly, the threshold DS above which the powders formed a solution were reduced for both products of the two routes. Pre-mechanical (RBP-cm, route 2) and post-mechanical (RBP-mc, route 1) carboxymethylation led to products which were soluble in water above a DS of 0.2 and 0.22 , respectively. RBP-c was soluble above a DS of 0.27 which is close to the reported value of 0.3 Walecka (1956). Figure 7b shows the range of DS values covered for the preparation of redispersible carboxymethylated cellulose nanofibrils (light grey, striped) reported in patents (Excoffier et al. 1999; Cash et al. 2003 and Bahia 1995). In addition, the "preferred values" of DS indicated in the patents are highlighted (dark grey, striped). The experimentally determined range of DS to yield stable suspensions of water-redispersible, nanofibrillated cellulose in powder form coincides with the preferred values from the references.

\section{Conclusions}

Water-redispersible, nanofibrillated cellulose in powder form was prepared from refined, bleached beech pulp (RBP) by carboxymethylation (c) and mechanical disintegration $(\mathrm{m})$. Two routes were examined, leading to four different products. In route 1, the RBP was mechanically disintegrated (RBP-m), followed by carboxymethylation (RBP-mc) with a DS of 0.09 . In route 2 , the sequence of the chemical and mechanical treatment was reversed, leading to the RBP-c and RBP-cm products with a DS of 0.13 and 0.14 , respectively.

FT-IR and CP-MAS ${ }^{13}$ C-NMR spectroscopy proved the occurrence of the carboxymethylation reaction of the RBP-mc, RBP-c and RBP-cm products with the appearance of characteristic signals for the carboxylate group at $1,595 \mathrm{~cm}^{-1}$ and $180 \mathrm{ppm}$, respectively. Also, mechanical disintegration of the RBP (RBP-m) did not lead to a change in chemical structure since the FT-IR and the ${ }^{13} \mathrm{C}$ solid state NMR spectra were identical.

XRD experiments showed a loss of crystallinity for the carboxymethylated samples, and this effect was especially pronounced for the products of route 2. Mechanical disintegration of the untreated RBP material did not significantly alter the crystalline structure. Also, TGA experiments evidenced a dramatic decrease in thermal stability of the carboxymethylated samples, since the onset temperature of the cellulose degradation dropped from 300 to $200{ }^{\circ} \mathrm{C}$. This will limit the use of the final RBP products in nanocomposites to those biopolymers that do not require processing temperatures above $200{ }^{\circ} \mathrm{C}$ during extrusion.

On the other hand, SEM and sedimentation tests confirmed that carboxymethylation was essential to obtain water-redispersible powders, capable of forming stable suspensions. Specifically, samples that were first carboxymethylated (those from route 2) formed a more transparent suspension in water and showed a more homogeneous network with overall diameters below $1 \mu \mathrm{m}$ (RBP-c and RBP-cm). Mechanical disintegration of the RBP (RBP-m) improved dispersibility in water compared to the untreated RBP but it was not very stable as it phaseseparated with time.

These results demonstrate that the water-redispersible RBP powders obtained in this work are an attractive alternative to the conventional nanofibrillated cellulose aqueous suspensions as starting material for the synthesis of novel cellulose nanocomposites. The powdered chemically modified RBP would not only allow reducing storage volume and shipping costs but also they would increase the storage life of the product against bacterial degradation. Furthermore, the generated carboxylate groups on the surface of the derivatized RBP could undergo further chemical modification (e.g. esterification) to enhance the chemical affinity of the fibrils to a specific non-polar matrix.

Acknowledgments The authors wish to express their thanks to Beatrice Fischer, as well as Urs Gfeller and Dr. Peter Lienemann for performing the TGA and XRD measurements, respectively and Dr. Philippe Tingaut for carefully reading the manuscript. The authors gratefully acknowledge the State Secretariat for Education and Research (SER) for financial support of this work. 


\section{References}

Abe K, Iwamoto S, Yano H (2007) Obtaining cellulose nanofibers with a uniform width of $15 \mathrm{~nm}$ from wood. Biomacromolecules 8:3276-3278

Andresen M, Johansson LS, Tanem BS, Stenius P (2006) Properties and characterization of hydrophobized microfibrillated cellulose. Cellulose 13:665-677

Araki J, Wada M, Kuga S (2001) Steric stabilization of a cellulose microcrystal suspension by poly(ethylene glycol) grafting. Langmuir 17:21-27

Bahia HS (1995) Treatment of cellulose. Patent publication number WO9515342

Boldizar A, Klason C, Kubat J (1987) Prehydrolyzed cellulose as reinforcing filler for thermoplastics. Int J Polym Mater 11:229-262

Bordeanu N, Eyholzer Ch, Zimmermann T (2008) Cellulose nanostructures with tailored functionalities. Pending patent

Cantiani R, Guerin G, Senechal A, Vincent I, Benchimol J (2001) Patent publication numbers US6224663, US6231657, US6306207

Cash MJ, Chan AN, Conner HT, Cowan PJ, Gelman RA, Lusvardi KM, Thompson SA, Tise FP (2003) Derivatized microfibrillar polysaccharide. Patent publication number WO0047628

Chakraborty A, Sain M, Kortschot M (2006) Reinforcing potential of wood pulp-derived microfibres in a PVA matrix. Holzforschung 60:53-58

Couderc S, Ducloux O, Kim BJ, Someya T (2009) A mechanical switch device made of a polyimide-coated microfibrillated cellulose sheet. J Micromech Microeng 19:055006

Cuba-Chiem LT, Huynh L, Ralston J, Beattie DA (2008) In situ particle film ATR FTIR spectroscopy of carboxymethyl cellulose adsorption on talc: binding mechanism, $\mathrm{pH}$ effects, and adsorption kinetics. Langmuir 24:80368044

Dinand E, Chanzy H, Vignon M, Maureaux A, Vincent I (1996) Microfibrillated cellulose and method for preparing same from primary wall plant pulp, particularly sugar beet pulp. Patent publication number WO9624720

Excoffier G, Vignon M, Benchimol J, Vincent I, Hannuksela T, Chauve V (1999) Parenchyma cellulose substituted with carboxyalkyl groups and preparation method. Patent publication number WO9938892

Eyler RW, Klug ED, Diephuis F (1947) Determination of degree of substitution of sodium carboxymethylcellulose. Anal Chem 19:24-27

Fukuzumi H, Saito T, Iwata T, Kumamoto Y, Isogai A (2009) Transparent and high gas barrier films of cellulose nanofibers prepared by TEMPO-mediated oxidation. Biomacromolecules 10:162-165

Gilardi G, Abis L, Cass AEG (1995) Carbon-13 CP/MAS solid-state NMR and FT-IR spectroscopy of wood cell wall biodegradation. Enzyme Microb Technol 17:268275

Goussé C, Chanzy H, Cerrada ML, Fleury E (2004) Surface silylation of cellulose microfibrils: preparation and rheological properties. Polymer 45:1569-1575
Heinze T, Koschella A (2005) Carboxymethyl ethers of cellulose and starch - a review. Macromol Symp 223:13-39

Herrick FW (1984) Process for preparing microfibrillated cellulose. Patent publication number US4481077

Herrick FW, Casebier RL, Hamilton JK, Sandberg KR (1983) Microfibrillated cellulose: morphology and accessibility. J Appl Polym Sci: Appl Polym Symp 37:797-813

Hubbe MA, Rojas OJ, Lucia LA, Sain M (2008) Cellulosic nanocomposites: a review. Biores 3:929-980

Hult EL, Larsson PT, Iversen T (2001) Cellulose fibril aggregation-an inherent property of kraft pulps. Polymer 42:3309-3314

Kono H, Yunoki S, Shikano T, Fujiwara M, Erata T, Takai M (2002) CP/MAS ${ }^{13} \mathrm{C}$ NMR study of cellulose and cellulose derivatives. 1. Complete assignment of the CP/MAS ${ }^{13} \mathrm{C}$ NMR spectrum of the native cellulose. J Am Chem Soc 124:7506-7511

Laivins GV, Scallan AM (1993) The mechanism of hornification of wood pulps. In: Proc 10th fundamental research sympoisum. Oxford, pp 1235-1260

Lasseuguette E (2008) Grafting onto microfibrils of native cellulose. Cellulose 15:571-580

Lindström T, Carlsson G (1982) The effect of carboxyl groups and their ionic form during drying on the hornification of cellulose fibers. Svensk Papperstidning 85:R146-R151

Lourdes-Leza M, Cortazar M, Casinos I, Guzmán GM (1989) Thermal degradation of partially carboxymethylated cellulose grafted with 4-vinylpyridine. Angew Makromol Chem 168:195-203

Pääkkö M, Ankerfors M, Kosonen H, Nykänen A, Ahola S, Österberg M, Ruokolainen J, Laine J, Larsson PT, Ikkala O, Lindström T (2007) Enzymatic hydrolysis combined with mechanical shearing and high-pressure homogenization for nanoscale cellulose fibrils and strong gels. Biomacromolecules 8:1934-1941

Proniewicz LM, Paluszkiewicz C, Weselucha-Birczyńska A, Majcherczyk H, Barański A, Konieczna A (2001) FT-IR and FT-Raman study of hydrothermally degradated cellulose. J Mol Struct 596:163-169

Reid JD, Daul GC (1947) The partial carboxymethylation of cotton to obtain swellable fibers, I. Text Res J 17: 554-561

Saito T, Nishiyama Y, Putaux JL, Vignon M, Isogai A (2006) Homogeneous suspensions of individualized microfibrils from TEMPO-catalyzed oxidation of native cellulose. Biomacromolecules 7:1687-1691

Sassi JF, Chanzy H (1995) Ultrastructural aspects of the acetylation of cellulose. Cellulose 2:111-127

Scallan AM, Tigerström AC (1992) Swelling and elasticity of the cell walls of pulp fibres. J Pulp Pap Sci 18:188-193

Segal L, Creely JJ, Martin AE Jr, Conrad CM (1959) An empirical method for estimating the degree of crystallinity of native cellulose using the X-Ray diffractometer. Text Res J 29:786-794

Shafizadeh F, McGinnis GD (1971) Chemical composition and thermal analysis of cottonwood. Carbohydr Res 16: 273-277

Stenstad P, Andresen M, Tanem BS, Stenius P (2008) Chemical surface modifications of microfibrillated cellulose. Cellulose 15:35-45 
Turbak AF, Snyder FW, Sandberg KR (1983) Microfibrillated cellulose, a new cellulose product: properties, uses, and commercial potential. J Appl Polym Sci: Appl Polym Symp 37:815-823

Wågberg L, Winter L, Ödberg L, Lindström T (1987) On the charge stoichiometry upon adsorption of a cationic polyelectrolyte on cellulosic materials. Colloid Surfaces 27:163-173

Wågberg L, Decher G, Norgren M, Lindström T, Ankerfors M, Axns K (2008) The build-up of polyelectrolyte multilayers of microfibrillated cellulose and cationic polyelectrolytes. Langmuir 24:784-795

Walecka JA (1956) An investigation of low degree of substitution carboxymethylcelluloses. Tappi 39:458-463
Yano H, Nakahara S (2004) Bio-composites produced from plant microfiber bundles with a nanometer unit web-like network. J Mater Sci 39:1635-1638

Yano H, Sugiyama J, Nakagaito AN, Nogi M, Matsuura T, Hikita M, Handa K (2005) Optically transparent composites reinforced with networks of bacterial nanofibers. Adv Mater 17:153-155

Young RA (1994) Comparison of the properties of chemical cellulose pulps. Cellulose 1:107-130

Zadorecki P, Michell AJ (1989) Future-prospects for wood cellulose as reinforcement in organic polymer composites. Polym Compos 10:69-77 